\title{
MENGELOLA SAMPAH MENJADI PUPUK KOMPOS DI KELURAHAN RANTAU PANJANG RUMBAI PEKANBARU
}

\author{
Rahmat Tisnawan 1), M. Fajar Anugrah 2), Husnah ${ }^{3)}$ \\ ${ }^{1,3)}$ Program Studi Teknik Sipil Universitas Abdurrab \\ ${ }^{2)}$ Program Studi Ilmu Pemerintahan Universitas Abdurrab \\ Email: husnah@univrab.ac.id
}

\begin{abstract}
ABSTRAK
Mengelola sampah merupakan kegiatan konversi sampah yang tidak berguna atau limbah menjadi berguna berguna secara efisien dan ekonomis dengan dampak lingkungan seminimal mungkin. Oleh karena itu dibutuhkan informasi tentang karakter sampah, karakter teknis teknologi konversi yang ada, karakter pasar dari produk pengolahan, implikasi lingkungan, persyaratan lingkungan, dan ketersediaan dana. Tujuan pengabdian ini adalah mewujudkan kelurahan yang green and clean dikemas dalam paket pengabdian masyarakat oleh Tim dosen Universitas Abdurrab. LangkahLangkah Kegiatan Adapun langkah-langkah kegiatan yang dilakukan adalah pelatihan intensif melalui tahapan sebagai berikut: 1. Ceramah tentang kajian sistem pengelolaan sampah. 2. Ceramah tentang mengelola dan mengolah sampah rumah tangga, terutama Komposting metode $3 \mathrm{R}$ (Reduce, Reuse, Recycle). 3. Demonstrasi tentang penerapan Bank Sampah. 4. Latihan pemilahan sampah dan penerapan komposter. 5. Konsultasi dalam mengatasi beberapa kendala yang dihadapi peserta dalam pengelolaan sampah rumah tangga. 6 . Budaya gotong royong ditengah masyarakat.
\end{abstract}

Kata kunci: Sampah, komposter, reduce, reuse, recycle

\section{ABSTRACT}

Managing waste is a waste conversion activity that is not useful or the waste becomes useful useful efficiently and economically with minimal environmental impact. Therefore we need information about the character of waste, the technical character of existing conversion technology, the market character of processing products, environmental implications, environmental requirements, and availability of funds. The purpose of this service is to create a green and clean village that is packaged in a community service package by the Abdurrab University lecturer team. Activity Steps The activity steps taken are intensive training through the following stages:1. Lecture on the study of waste management systems.2. Lecture on managing and processing household waste, especially Composting the $3 R$ method (Reduce, reuse, recycle) 3 . Demonstration regarding the application of the Garbage Bank 4. Exercise on sorting waste and applying composter 5. Consultation in overcoming several obstacles faced by participants in managing household waste. 6. Mutual cooperation among the community.

Keywords: Garbage, composter, reduce, reuse, recycle 


\section{PENDAHULUAN \\ Pengolahan Sampah}

Permasalahan lingkungan hidup yang terjadi adalah penurunan daya dukung lingkungan karena rendahnya kesadaran masyarakat terhadap pentingnya pengelolaan lingkungan hidup. Hal ini disebabkan oleh beberapa faktor, antara lain perubahan fungsi dan tatanan lingkungan, penurunan daya dukung lingkungan dan mutu lingkungan, tidak adanya keterpaduan pengelolaan sumber daya manusia, alam, dan buatan dalam pengelolaan lingkungan hidup antar berbagai pihak, kurang optimalnya pemanfaatan ruang kota, serta pencemaran lingkungan yang dihasilkan oleh adanya sampah (Pengabdian et al., 2008).

Perkembangan ilmu pengetahuan dan teknologi khususnya teknologi informasi pada saat ini sangat mendukung dalam penyediaan informasi lingkungan. Melalui teknologi internet, informasi mengenai permasalahan lingkungan dan penanganannya dapat dilakukan dengan mudah. Kebijakan Otonomi Daerah sebagaimana dirumuskan dalam Undang-Undang Nomor 22 Tahun 1999, menegaskan adanya otoritas pemerintah daerah untuk mengurus dan mengelola berbagai sektor pembangunan dengan inisiatif dan prakarsa kreatif bagi kepentingan dan kesejahteraan rakyat daerah. Kota Pekanbaru sebagai titik berat otonomi daerah mendapat beban tanggung jawab yang relatif besar dibanding era sebelumnya (Agency, Sampah, \& Masyarakat, 2008).

Pengabdian kepada masyarakat dipandang perlu dilakukan sebagai sarana untuk menjembatani kampus dengan masyarakat. Sebagai realisasi pelaksanaan pengabdian kepada masyarakat bagi dosen-dosen di Universitas Abdurrab yang saat ini diperlukan oleh masyarakat adalah pengelolaan dan pengolahan sampah rumah tangga dengan metode sederhana. Tujuan pengabdian ini adalah mewujudkan kelurahan yang green and clean dikemas dalam paket pengabdian masyarakat oleh Tim dosen Universitas Abdurrab.

\section{Identifikasi Dan Perumusan Masalah}

Berdasarkan uraian pada analisis situasi dapat diidentifikasi sejumlah masalah sebagai berikut:

a. Banyaknya sampah rumah tangga di wilayah Kecamatan Rumbai Kota Pekanbaru, terutama di sekolah-sekolah dan lingkungan pemukiman penduduk.

b. Masyarakat belum memahami tentang pemilahan sampah.

c. Masyarakat belum memahami tentang teknik pengolahan sampah yang benar.

d. Masyarakat belum memahami tentang nilai guna sampah setelah dilakukan pengolahan.

Perumusan Masalah Berdasarkan pertimbangan urgensi permasalahan yang teridentifikasi di atas, maka dipilih dua masalah yang hendak dicari solusinya melalui kegiatan pelatihan ini. Dari masalah-masalah tersebut dapat dirumuskan masalah sebagai berikut:

a. Bagaimanakah cara pengelolaan dan pengolahan sampah rumah tangga terutama sampah yang berada di masyarakat

b. Kendala-kendala apakah yang menghambat masyarakat sekolah dalam pengelolaan dan pengolahan sampah rumah tangga terutama dilingkungan warga.

\section{Tujuan Kegiatan Pengabdian}

Tujuan diselenggarakannya kegiatan pengabdian kepada masyarakat ini adalah: 
1. Membekali ibu-ibu masyarakat rantau panjang cara pengelolaan dan pengolahan sampah rumah tangga, terutama sampah yang berada di lingkungan perumahan secara benar.

2. Memberikan gambaran dan demonstrasi tentang pengelolaan dan pengolahan sampah secara sederhana.

\section{Manfaat Kegiatan} adalah:

Manfaat yang diharapkan dari kegiatan pengabdian kepada masyarakat ini

1. Memberikan keterampilan kepada masyarakat dalam pengolahan sampah secara sederhana, baik di rumah maupun di pemukiman penduduk.

2. Sebagai wahana untuk meningkatkan pengetahuan dan wawasan dalam manajemen pengelolaan dan pengolahan sampah.

3. Sebagai forum untuk bertukar pikiran antara masyarakat dengan perguruan tinggi dalam pengelolaan dan pengolahan sampah yang berbasis budaya sehingga dapat diterapkan kedalam masyarakat maupun sekolah

\section{Masyarakat Sasaran}

Masyarakat sasaran kegiatan pengabdian ini adalah masyarakat di kelurahan Rantau Panjang yaitu ibu-ibu di pemukiman penduduk

\section{TINJAUAN PUSTAKA \\ Pengolahan Sampah}

Teknik pengelolaan sampah terpadu merupakan cara terbaik untuk mengolah sampah dengan prinsip 3R (reduce, reuse, dan recycle). Sebelum diolah, jenis sampah disortir antara yang bisa digunakan lagi (dengan pengolahan maupun tidak) dan yang benar-benar dibuang. Sampah yang dapat digunakan lagi dapat menghasilkan produk, sedangkan sisanya di olah dengan penguraian, pembakaran (misalnya dengan incenerator), dan penimbunan. Teknik ini sangat menghemat volume limbah akhir, tetapi memerlukan modal dan biaya operasional yang besar. (Mulyono Sadyohutomo, 2008).

Konsep pengelolaan sampah berbasis masyarakat sendiri harus disertai denganpemberdayaan masyarakat. pemberdayaan masyarakat dalam hal ini adalah menjadikanmasyarakat agar memiliki daya atau power untuk dapat mengelola sampahagarmenjadisesuatu yang berguna dan bernilai jual. Seperti yang dikemukakan oleh Edi Suharto bahwa pemberdayaan merujuk pada kemampuan orang sehingga mereka memiliki kemampuan dalam memenuhi kebutuhan dasar, meningkatkan pendapatan,dan agar dapat berpartisipasi dalam proses pembangunan. (Edi Suharto, 2009).

Menurut penelitian Adrianus dkk di Gunung Sarik Kota Padang, peningkatan partisipasi masyarakat dalam pengelolaan sampah dapat meningkatkan kualitas kesehatan masyarakat yang pada akhirnya meningkatkan kualitas SDM. (Adrianus, F., Sumarni, L., Kamami, N, 2010) Perempuan terutama ibu diharapkan lebih banyak mendapat informasi mengenai masalah lingkungan dan produk produk yang menyebabkan masalah lingkungan. Peran serta media massa dalam menyebarluaskan informasi mengenai masalah lingkungan cukup efektif untuk menjadikan wanita sebagai konsumen sadar lingkungan sehingga mempengaruhi jumlah sampah yang dihasilkan. (Rahmawaty, 2004) 
Peran serta masyarakat diharapkan mulai dari 3R. Contoh pelaksanaan kegiatan reduce adalah furoshiki, yaitu seni melipat kain yang berasal dari Jepang dengan cara membuat kantong dari kain untuk membawa barang keperluan sehari hari. Jika tidak digunakan, kain dapat dilipat rapi dan disimpan dalam tas tangan atau kantong pakaian. Kegiatan ini akan mengurangi jumlah sampah kantong plastik yang biasanya selalu digunakan untuk membawa barang. Contoh lainnya adalah membeli produk isi ulang agar dapat dimasukkan dalam wadah lama dan lain sebagainya. Contoh pelaksanaan reuse adalah menggunakan kembali wadah atau kemasan untuk sebagai wadah tempat lain seperti bekas botol minuman menjadi wadah minyak goreng, bungkus detergen menjadi pot bunga, kalengmakanan menjadi wadah makanan lain dan lain lain, menggunakan batrai yang dapat dicharge kembali, menjual belikan sampah yang telah terpilah kepada pihak yang memerlukan. Kegiatan recycle dapat berupa membuat kompos dari sampah organik, membuat kerajinan tangan dari sampah anorganik dan lanlain. Memanfaatkan sampah anorgani kmemerlukan kreatifitas dan pembinaan khususnya dari PKK. Pemantauan dan evaluasi oleh BPLH masih dilakukan untuk sampah pasar dan belum untuk rumah tangga. Pemantauan dan evaluasi pengelolaan sampah hendaknya dilakukan bersama oleh pemerintah dan masyarakat. Jika tidak dilakukan pemantauan sampah akan menumpuk. Hal ini akan menyebabkan berbagai banyak masalah kesehatan dan menimbulkan gas $\mathrm{CH} 4$ sehingga dapat menimbulkan perubahan iklim dan meningkatkan masalah lingkungan.

(Sudarman, 2010) Dalam rangka pemberdayaan masyarakat dibutuhkan kontribusi dari masing-masing aktor yaitu pemerintah, masyarakat dan swasta untuk membentuk suatu model kemitraan yang diharapkan. Peran pemerintah lebih banyak pada penentuan rambu-rambu dan aturan main secara umum. Pihak swasta berperan pada implementasi penentuan langkah (policy action) bersama masyarat. Sedangkan masyarakat berperan dalam bentuk partisipasi, baik pada level formulasi, implementasi, monitoring maupun evaluasi. Membentuk suatu kemitraan bertujuan untuk mencapai hasil yang lebih baik, dengan saling memberikan manfaat antar pihak yang bermitra. Bantuk kemitraan mengambil pemahaman dari dunia organisme dibedakan menjadi Pseudo Partnership (KemitraanSemu), Mutualism Partnership (KemitraanMutualistik), Conjugation Partnership (Kemitraan melalui Peleburan dan Pengembangan). Sedangkan fenomena fenomena hubungan kerjasama antar organisasi adalah mencakup Subordinate Union of Partnership, Linear Union of Partnership, Linear Collaborative of Partnership. (Ambar Teguh Sulistiyani, 2004)

\section{METODE PELAKSANAAN}

\section{Langkah-langkah Kegiatan}

Metode kegiatan yang digunakan dalam pelatihan mencakup paling tidak 2 (dua) metode, yaitu:

1. Ceramah bervariasi metode ini dipilih untuk menyampaikan konsep-konsep yang penting untuk dimengerti dan dikuasai oleh peserta pelatihan. Penggunaan metode ini dengan pertimbangan bahwa metode ceramah yang dikombinasikan dengan gambar-gambar, animasi, dan dengan memanfaatkan display, dapat memberikan materi yang relatif banyak secara padat, cepat, dan mudah. Ceramah meliputi ceramah tentang kajian sistem pengelolaan sampah perkotaan dan ceramah tentang mengelola dan mengolah sampah rumah tangga.

2. Demonstrasi metode demonstrasi dipilih untuk menunjukkan suatu proses kerja pengolahan sampah rumah tangga sehingga dapat dapat memberikan kemudahan 
bagi peserta pelatihan. Demonstrasi tentang penerapan 3R dilakukan oleh pelatih atau nara sumber.

Adapun langkah-langkah kegiatan yang dilakukan adalah pelatihan intensif melalui tahapan sebagai berikut:

1. Ceramah tentang kajian sistem pengelolaan sampah perkotaan.

2. Ceramah tentang mengelola dan mengolah sampah rumah tangga, terutama Komposting metode $3 \mathrm{R}$ (Reduce, reuse, recycle)

3. Demonstrasi tentang penerapan Bank Sampah

4. Latihan pemilahan sampah dan penerapan Lobang Biopori

5. Konsultasi dalam mengatasi beberapa kendala yang dihadapi peserta dalam pengelolaan sampah rumah tangga.

6. Budaya gotong royong ditengah masyarakat.

\section{Faktor Pendukung dan Penghambat}

Berdasarkan survey dapat diidentifikasi faktor pendukung dan penghambat dalam melaksanakan program pengabdian masyarakat ini. Secara garis besar faktor pendukungdan penghambat adalah sebagai berikut:

1. Faktor Pendukung

a. Tersedia tenaga ahli yang memadai dalam bidang lingkungan di Universitas Abdurrab.

b. Adanya dosen di Universitas Abdurrab yang mempunyai keahlian dalam kajian sampah.

c. Antusiasme ibu-ibu yang cukup tinggi karena kebutuhan mereka untuk mengetahui cara pemilahan dan pengolahan sampah rumah tangga khususnya dilingkungan perumahan.

d. Dukungan lurah Rantau Panjang Rumbai yang menyambut baik pelaksanaan kegiatan pelatihan.

e. Ketersediaan dana pendukung dari fakultas sebagai pendukung penyelenggaraan kegiatan pengabdian masyarakat ini.

2. Faktor Penghambat

a. Masyarakat belum memiliki pengetahuan awal tentang pengelolaan dan pengolahan sampah rumah tangga khususnya dilingkungan.

b. Masyarakat sebagai peserta pelatihan belum dapat memilah dan membuat kompos dengan metode yang disampaikan karena ketidakpahaman terkait untuk penanganan sampah.

\section{Jadwal Pelaksanaan}

Kegiatan dilaksanakan di Kelurahan Rantau Panjang, pada hari Minggu, tanggal 28 Juli 2019 Jam 9.00 - 16.00. Jenis kegiatan yang dilakukan sosialisasi dan pelatihan pengolahan sampah.

\section{HASIL DAN PEMBAHASAN}

Pelaksanaan dari kegiatan pengabdian kepada masyarakat dapat berjalan dengan lancar. Pelatihan Pengolahan sampah Berbasis Masyarakat Di Kelurahan Rantau Panjang Rumbai Pekanbaru berjalan sesuai rencana. Dari kegiatan yang dilakukan, Warga masyarakat Rantau Panjang mendapatkan ilmu dan wawasan tentang pengolahan 
sampah, dan warga masyarakat sangat antusias dalam mendengarkan pemaparan materi terkait dengan pengolahan sampah yang di sampaikan oleh moderator Husnah, MT dan materi di sampaikan oleh M. Fajar Anugerah, M.Si. tindaklanjut dari acara ini adalah implementasi dalam pengolahan sampah dan membuat bank sampah di kelurahan Rantau Panjang, Rumbai Pekanbaru. Pelaksanaan kegiatan dapat dilihat pada gambar berikut:

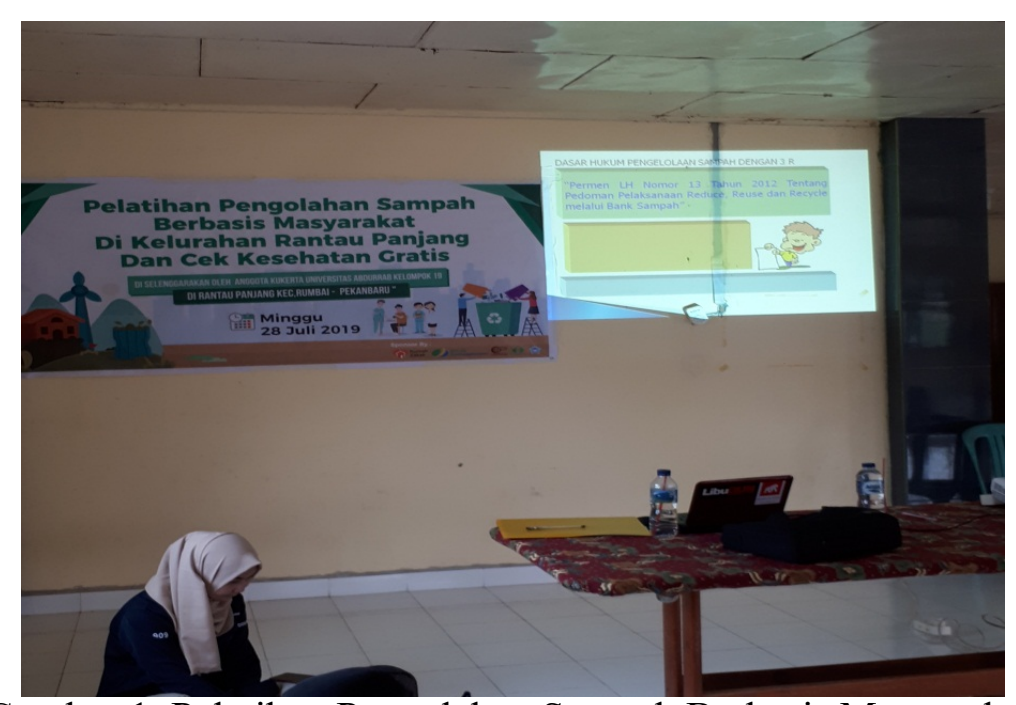

Gambar 1. Pelatihan Pengolahan Sampah Berbasis Masyarakat

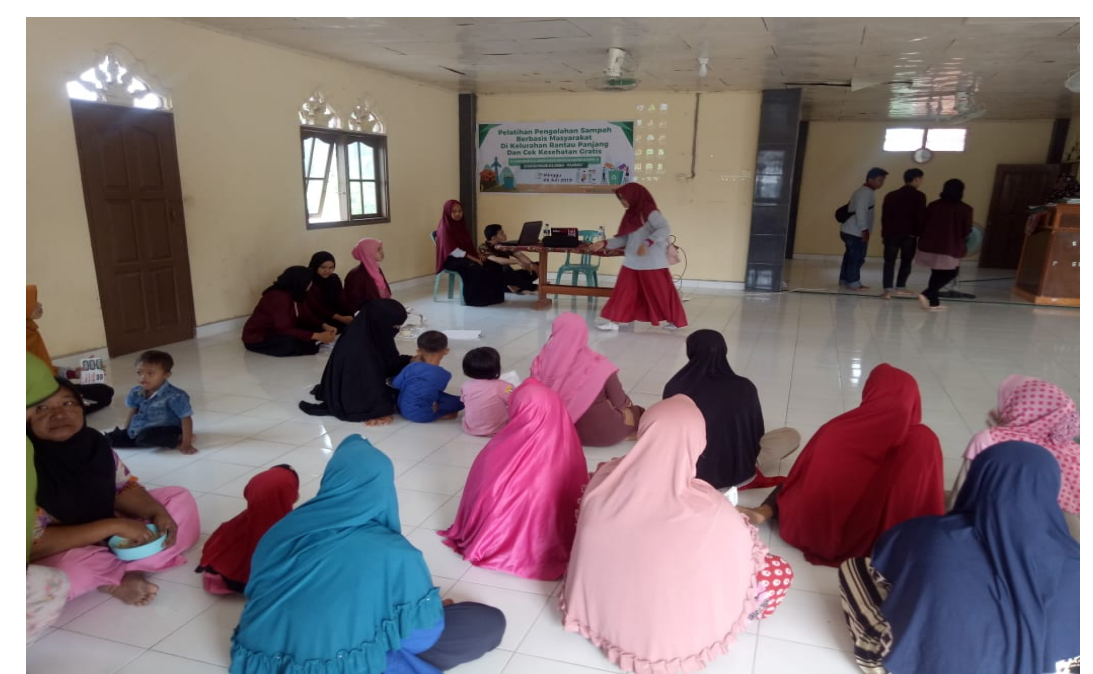

Gambar 2. Kegiatan Pelatihan Pengolahan Sampah

\section{KESIMPULAN}

1. Tim Pengabdian kepada Masyarakat dari Universitas Abdurrab telah berhasil melaksanakan Pelatihan Pengolahan sampah berbasis masyarakat di Kelurahan Rantau Panjang Rumbai Pekanbaru

2. Warga Masyarakat Kelurahan Rantau Panjang Rumbai Pekanbaru memberikan tanggapan yang antusias pada pelatihan ini dilihat dari jumlah warga yang hadir 
dan meminta segera menindaklanjuti untuk segera di implementasikan membuat pupuk kompos saat pelatihan

3. Terjalin kemitraan dan kerjasama antara pihak Universitas dan Kecamatan Rumbai.

\section{DAFTAR PUSTAKA}

[1]. Adrianus, F., Sumarni, L., Kamami, N. Pemberdayaan Masyarakat Melalui Peningkatan Partisipasi dalam Pengelolaan Sampah di Kelurahan Gunung Sarik Kecamatan Kuranji Kota Padang. Laporan Penelitian. Fakultas Ekonomi, Universitas Andalas. 2010

[2]. Agency, I. C., Sampah, P., \& Masyarakat, B. (2008). Pengelolaan sampah rumah tangga berbasis masyarakat - jica, 4-5.

[3]. Pengabdian, K., Masyarakat, P., Khotimah, N., Si, M., Hadi, B. S., \& Si, M. (2008). Rumah Tangga Berbasis Budaya Terhadap Guru Sekolah Dasar Di Kecamatan Wirobrajan ( Menuju Kota Jogja Green And Clean ), 1-27.

[4]. Rahmawaty. Persepsi Wanita Mengenai Pengelolaan Sampah di Lingkungan Kampus IPB Darmaga, Kabupaten Bogor. Laporan Penelitian. Fakultas Pertanian, Universitas Sumatera Utara. 2004

[5]. Sudarman. Meminimalkan Daya Dukung Sampah terhadap Pemanasan Global. Laporan Penelitian. Semarang: Fakultas Teknik, Universitas Negeri Semarang; 2010 